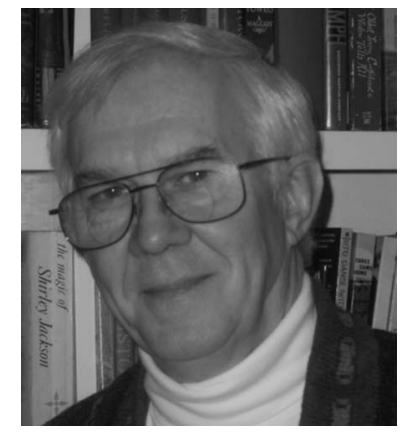

\section{Retirement +1}

It's been a year since I retired as a faculty member in the School of Physics at Georgia Tech. In this space last June I said I intended to get a paper off the corner of my desk and to begin a new text on optical engineering. Ah well, the paper is creeping in the direction of the center of the desk and the text is still in the resource gathering stage. You would think with all this time, I would be done with the paper and well along on the text. It turns out that's not the way retirement works. Things intervene.

One thing that no one ever told me about retirement is that the chickens that you have managed to keep busy out in the yard come home to roost. Many of the items that you have put off, squirreled away, or buried are now demanding attention. No longer can I dismiss file cabinets at home and at work with a wave of the hand. No longer can I continue to stuff another paper in with others that I might need some day. As my wife, Helen, puts it: "Someday is now."

With the beginning of retirement, papers, software, and notebooks take on a completely different importance. And while, at first, I didn't want to admit it, I didn't need most of it. My guiding principle became: If it wasn't important for the text, it went in the wastebasket. All the materials on diffractive optics were shipped up the interstate to my colleague and co-author of an SPIE tutorial text on diffractive optics, Tom Suleski, now a professor at the University of North Carolina at Charlotte.

Obviously Optical Engineering continues to take a good part of my time. In addition, I have been chairing a subcommittee on electronic journals for the SPIE Publications Committee. A short discussion of the issues we are addressing was given in my September 2004 editorial. This has proven to be interesting and challenging work.

So, where does all the time go? For one thing, I have the luxury of reading the New York Times at my computer each morning after thumbing through the print version of the Atlanta Journal-Constitution. Then there is the matter of "engineering" my garden, as I described in June. Then last July 5th we took on the job of contracting the remodeling of our kitchen after the experts dithered for three months. We will probably finish a year later.

I have begun to teach myself graphics design. In many cases my instruction comes by way of a series of projects that I take on. I tend to push the limits of my ability and go in search of Photoshop techniques that I can use to produce what I need. In one case I have figured out how to illustrate my wife's handbook on clinical nursing instruction and then apply the process to my daughter's ideas for personalized puppets.

But the largest and most satisfying segment of our time has been devoted to travel. In the past year Helen and I have spent almost three months on the road with two trips to Italy, a month in Australia and New Zealand, several weeks with the grandchildren, and we will finish it off with two weeks in Eastern Europe following the SPIE International Congress on Optics and Optoelectronics in Warsaw.

What have I learned about retirement this past year? First, don't wait to travel. Do it while you still have good knees and legs. We do very nicely for ourselves, but we don't cover territory the way we used to. Second, there is never enough time. You cannot do all the things you would like to do. Don't let that faze you, because additional opportunities will present themselves. You just have to resign yourself to picking and choosing from several enjoyable options.

And having stayed away from the School of Physics except to pick up mail and clean out the office during the past year, this fall I will teach a sophomore physics course. However, since I left they have added some new technology that gives remotes to all the students in the class and lets the prof ask them questions during the class and get responses from all those present. I've never done that before. It should be interesting.

Donald C. O'Shea Editor 